\title{
Effect of Feeding Space on the Inter-Cow Distance, Aggression, and Feeding Behavior of Free-Stall Housed Lactating Dairy Cows
}

\author{
T. J. DeVries, M. A. G. von Keyserlingk, and D. M. Weary \\ Animal Welfare Program, Faculty of Agricultural Sciences, \\ The University of British Columbia, Vancouver, V6T 1Z4, Canada
}

\begin{abstract}
The objectives of this study were to determine whether doubling the amount of feeding space from 0.5 to $1.0 \mathrm{~m}$ per cow leads to increased spacing between cows at the feeder, fewer aggressive social interactions among cows, and ultimately increased feeding activity. Twenty-four lactating Holstein cows were provided with 0.5 and $1.0 \mathrm{~m}$ of feeding space per cow in a $2 \times 2$ crossover design replicated over time. Time-lapse video was used to quantify the inter-cow distance and incidence of aggressive displacements at the feed alley. An electronic feed alley monitoring system was used to monitor the feeding behavior of the cows. When animals had access to $1.0 \mathrm{~m}$ per cow, there was at least $60 \%$ more space between animals and $57 \%$ fewer aggressive interactions while feeding than with access to $0.5 \mathrm{~m}$ of feeding space. These changes in spacing and aggressive behavior in turn allowed cows to increase feeding activity throughout the day, especially during the $90 \mathrm{~min}$ after providing fresh feed (an increase of $24 \%$ ). This increase in feeding activity was particularly evident for subordinate cows. These results indicate that increasing space allowance at the feeder increases feeding activity and reduces competition among lactating dairy cows.
\end{abstract}

(Key words: feeding space, feeding behavior, dairy cow)

Abbreviation key: $\mathbf{P F}=$ postfeeding.

\section{INTRODUCTION}

Dairy cows in North America are commonly housed in free-stall barns with approximately $0.6 \mathrm{~m}$ of feed alley space per cow (Grant and Albright, 2001). Research on feeding space has concluded that cows can be kept with as little as $0.2 \mathrm{~m}$ of feeding space per cow without adversely affecting DMI or milk production (e.g., Friend et al., 1977; Collis et al., 1980). However,

Received September 15, 2003

Accepted December 10, 2003.

Corresponding author: T. J. DeVries; e-mail: trevorjd@ interchange.ubc.ca. increased animal densities are linked to reduced interindividual distances and increased aggressive behavior (Keeling and Duncan, 1989; Kondo et al., 1989), perhaps limiting the ability of some cows to feed.

Under extensive grazing systems, cattle will often synchronize their behavior; that is, many animals in the group will feed, ruminate, and rest at the same times (Miller and Wood-Gush, 1991; Rook and Huckle, 1995). Studies have shown, however, that the synchronization of behaviors may be reduced when cattle are housed intensively indoors (O'Connell et al. 1989; Miller and Wood-Gush, 1991), perhaps because of competition for space or resources. For example, Friend and Polan (1974) reported that only $66 \%$ of cows could eat at one time when provided with $0.5 \mathrm{~m}$ of feed alley space, and recent work by our group has found that when given $0.6 \mathrm{~m}$ of feed alley space per cow, fewer than $70 \%$ of animals feed simultaneously (DeVries et al., 2003a). These findings suggest that space availability limits animals from feeding together, particularly during popular eating times. If feeding space is limited, increased competition among cows at the feeder may lead to some cows modifying their feeding times to avoid aggressive interactions (Miller and Wood-Gush, 1991). In this case, subordinate cows would likely be most limited in their access to feed during peak feeding times (Friend and Polan, 1974). It has also been suggested that increased feeding competition may reduce intake and increase feeding rate, possibly increasing the risk for metabolic problems such as left displaced abomasums and subacute ruminal acidosis (Shaver, 1997; Shaver, 2002).

The objectives of the current study were to determine whether doubling the amount of feeding space from 0.5 to $1.0 \mathrm{~m}$ per animal leads to more space between cows at the feeder and fewer aggressive social interactions among cows, ultimately allowing cows to increase their feeding activity, particularly at peak feeding times. In addition, we evaluated whether subordinate cows are more affected by space availability.

\section{MATERIALS AND METHODS}

\section{Animals, Housing, and Diet}

Two primiparous and 22 multiparous (parity $=2.95$ \pm 1.25 ; mean $\pm \mathrm{SD}$ ) lactating Holstein dairy cows were 
used in the study. The animals were $85.3 \pm 7.0 \mathrm{DIM}$ at the beginning of the data collection period and had an average milk yield of $46.1 \pm 8.0 \mathrm{~kg} / \mathrm{d}$ over the course of the experiment. The cows were housed in a free-stall barn located at The University of British Columbia Dairy Education and Research Centre (Agassiz, BC, Canada) and were managed according to the guidelines set by the Canadian Council on Animal Care (1993). The cows were fed a TMR consisting of $30 \%$ corn silage, $8 \%$ grass silage, $4 \%$ alfalfa hay, $5 \%$ third-cut grass hay, $16 \%$ steam-rolled corn, and $37 \%$ concentrate mash on a DM basis. The TMR was formulated according to the National Research Council (2001) nutrient requirement recommendations for high producing dairy cows. Cows were fed from a feed alley with access via a pendulous feed rail. Animals were fed daily at approximately 0600 and $1600 \mathrm{~h}$ and were milked at approximately 0700 and $1700 \mathrm{~h}$ daily. Feed was pushed up closer to the cows at 1100 and $2200 \mathrm{~h}$ daily.

\section{Experimental Treatments and Design}

The 24 lactating cows were used in a $2 \times 2$ crossover design replicated over time. The animals were divided into 4 equal groups of 6 cows, which were balanced according to projected 305-d milk production (12,645 \pm $1486 \mathrm{~kg}$; mean $\pm \mathrm{SD})$, average DIM (85.3 \pm 7.0$)$, and average parity. Experimental treatments consisted of either 0.5 or $1.0 \mathrm{~m}$ of feed alley space per animal. The 0.5-m treatment approximated the minimum standard typically recommended (Grant and Albright, 2001). The 1.0-m treatment was selected to provide a contrast within a range that is still relevant to producers.

Two adjacent pens, each having a total of $6 \mathrm{~m}$ of accessible feed alley space and 12 free stalls filled with $40 \mathrm{~cm}$ of washed river sand, were used in the study. In each pen, the 12 stalls were configured in 3 rows. Two rows faced one another, were open at the front (headto-head), and had a stall length of $240 \mathrm{~cm}$. Two of these stalls were chained off to prevent access by cows, as was the entire back row of 4 stalls, such that 6 stalls were available for each group of 6 cows.

At the start of the first replication, one group had access to $0.5 \mathrm{~m}$ of feed alley space per cow, and the adjacent group had $1.0 \mathrm{~m}$ of feed alley space per cow. The $0.5 \mathrm{~m}$ of feed alley space per cow was achieved by placing a concrete partition $(60 \mathrm{~cm} \times 60 \mathrm{~cm} \times 90 \mathrm{~cm})$ midway along the feed alley. When this partition was in place, feed was placed only on the half of the feed alley furthest from the adjacent pen, with $1.0 \mathrm{~m}$ of feeding space per cow. Each group was fed at the same time, and feed was evenly distributed along the available feed alley space.
Groups were exposed to each treatment for a 2-d adjustment period, followed by $7 \mathrm{~d}$ of data collection. The feed alley space allowance was then switched for the 2 groups by moving the concrete partition from the feed alley of the one pen to the feed alley of the adjacent pen. Again, animals had a 2-d adjustment period followed by $7 \mathrm{~d}$ of observations on the new treatment. This same procedure was then repeated with the 2 remaining groups of cows.

\section{Behavioral Recording}

Distance between individuals, number of displacements, and feeding behavior of the cows at the feed alley were recorded for $7 \mathrm{~d}$ per treatment. Spacing and aggressive behavior was monitored using time-lapse video equipment. The animals were videotaped using one video camera (Panasonic WV-BP330, Panasonic, Osaka, Japan) per pen, a time-lapse videocassette recorder (Panasonic AG-6540), and a video multiplexer (Panasonic WJ-FS 216). The video cameras were located $6 \mathrm{~m}$ above the feed alley, and red lights $(100 \mathrm{~W})$ were used to facilitate recording at night. Individual animals were identified on the back with unique alphanumeric symbols made with black or blonde hair dye (Clairol's Nice and Easy \#122, Natural Black, or Clairol's L'image Maxiblonde, Clairol, Stamford, CT), depending on hair color. Feeding behavior was monitored for the entire experiment using an electronic feed alley monitoring system (GrowSafe Systems Ltd., Airdrie, $\mathrm{AB}, \mathrm{Canada}$ ) that recorded individual cow presence (hits: a reading that occurs every $6 \mathrm{~s}$ for the duration of time the cows is standing at the feed alley) at the feed alley. This system has previously been described (DeVries et al., 2003b) and validated (DeVries et al., 2003c).

Inter-cow distances and aggressive displacements at the feed alley were recorded during the 90 -min period following the $2 \times \mathrm{d}$ provision of fresh feed. Feed was either provided when the cows were gone for milking or just prior to milking. The appearance of the first cow feeding on the fresh feed marked the beginning of these 90-min observation periods. In cases in which feed was available prior to milking, observations began after the feed was initially provided, were suspended during milking, and then resumed once the first animal had returned from the parlor and started to feed. This 90min postfeeding (PF) period has previously been identified as the time when the largest concentrations of cows are present at the feed alley (DeVries et al., 2003a).

Measuring inter-cow distance and aggressive displacements. To ensure a common reference point when measuring inter-cow distances, a cross made of reflective tape was glued onto the third thoracic verte- 
bra of each animal, identified by palpation from the left lateral side of each cow. The feed rail of both pens was marked with a permanent vertical line every $0.3 \mathrm{~m}$ on center. The cow's position was recorded by matching the reflective cross on the animal to the reference points on the neck rail, with the precision of one-half spacing between points $(0.15 \mathrm{~m})$. Observations of inter-cow distances and the number of animals present at the feed alley were made every 5 min for the $90-$ min PF period for each day of data collection.

Displacements from the feed alley within the 90-min $\mathrm{PF}$ period were also recorded. A displacement was noted when a butt or a push from the actor (instigator) resulted in the complete withdrawal of the reactor's head from beneath the feed rail. In addition to using the number of displacements as a dependent variable, these observations were also used to calculate an index of success in agonistic interactions for each individual cow. This index was calculated using the methods described by Mendl et al. (1992). Displacement data were combined from both treatments. The index of success was calculated as follows:

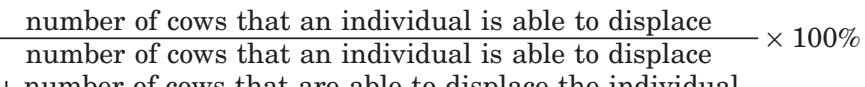

+ number of cows that are able to displace the individual

Measuring feeding behavior. The feeding behavior of individual cows was quantified using measures of daily feeding activity (hits per day), feeding intensity (hits per meal minute), and total daily mealtime (minutes per day), using the methods described by DeVries et al. (2003b). Estimates of mealtime rely on the use of a meal criterion, which is the minimum time interval between visits to the feed alley to consider the next feed alley visit as being part of a new meal. Therefore, a pooled meal criterion (26.41 $\mathrm{min}$ ) was calculated using the data from all 24 cows according to the methods described by DeVries et al. (2003b). All 3 measures, feeding activity, feeding intensity, and total daily mealtime were calculated for each cow for each treatment day. Feeding activity was also calculated for the 90min $\mathrm{PF}$ periods for each cow for each treatment day.

\section{Data Analysis}

For the analysis of inter-cow distances, displacements from the feed alley, and feeding behavior, the pen was considered as the experimental unit, with measures from multiple days and cows averaged to create one observation per pen per treatment. Inter-cow distances were further averaged for the number of cows that were present at the feed alley when each measurement was taken. There was a significant interaction between treatment and number of animals present at the feed alley for the inter-cow distance measurements; consequently, these data were analyzed separately for each number of animals present. Treatment effects on the inter-cow distances, number of displacements, and feeding behavior measures were tested by one-sample paired $t$-tests with $3 \mathrm{df}$.

Overall, treatment responses were tested using the pen as the experimental unit; however, we had a specific prediction that certain cows would respond differently in their PF feeding activity (feeding activity during the $90 \mathrm{~min}$ after provision of fresh feed) to the $1.0-\mathrm{m}$ treatment. Therefore, we used 2 within-cow methods to ascertain which cows had the greatest response in their $\mathrm{PF}$ feeding activity to the $1.0 \mathrm{~m}$ of feeding space. First, this measure was analyzed using the regression procedure of SAS (1985). The PF feeding activity of the cows with $1.0 \mathrm{~m}$ of feeding space were regressed against the $\mathrm{PF}$ feeding activity with $0.5 \mathrm{~m}$ of feeding space. To determine whether cows changed on average, the intercept was tested for difference from zero; to determine the extent of the change relative to the initial value, the slope was tested for difference from one. Second, the effect of treatment on $\mathrm{PF}$ feeding activity was evaluated using an analysis of covariance (SAS, 1985), using each cow's index of success as a covariate. The model tested the terms for index of success ( $1 \mathrm{df}$ ), cows ( $22 \mathrm{df}$ ), treatment ( $1 \mathrm{df}$ ), and the interaction between treatment and index of success ( $1 \mathrm{df}$ ) against the residual error ( $22 \mathrm{df}$ ).

\section{RESULTS}

\section{Inter-cow Distance}

The distance between neighboring cows ranged from 0.15 to $2.10 \mathrm{~m}$ for $0.5 \mathrm{~m}$ of feed alley space and from 0.30 to $4.20 \mathrm{~m}$ for $1.0 \mathrm{~m}$ of feed alley space. There was a significant interaction $(P<0.001)$ between the number of animals present at the feed alley and the average distance between animals. Therefore, the effect of feeding space on the distance between neighboring cows was analyzed separately for each density (Table 1). Regardless of the number of animals present at the feed alley, the average distance between cows was at least $60 \%$ greater at $1.0 \mathrm{~m}$ of feeder space per cow relative to the $0.5 \mathrm{~m}$ treatment. The smallest range in distance between neighboring cows $(0.30$ to $0.60 \mathrm{~m})$ was seen with 6 animals feeding with $0.5 \mathrm{~m}$ of feeding space per cow. The largest range in distance between neighbouring cows $(0.60$ to $4.20 \mathrm{~m})$ was seen with 2 animals feeding with $1.0 \mathrm{~m}$ of feeding space per cow.

\section{Displacements}

The frequency of displacements per 90-min PF period, as measured by the number of times a cow physi- 
Table 1. The inter-cow distance ${ }^{1}$ (in meters) with 0.5 and $1.0 \mathrm{~m}$ of allocated feed alley space per cow, with varying numbers of cows present at the feed alley. The least square standard error and $P$ values for the test of treatment are provided for each animal density.

\begin{tabular}{|c|c|c|c|c|}
\hline \multirow{2}{*}{$\begin{array}{l}\text { Number of } \\
\text { cows feeding }\end{array}$} & \multicolumn{2}{|c|}{ Feed alley space per cow } & \multirow[b]{2}{*}{ LS SE } & \multirow[b]{2}{*}{$P$} \\
\hline & $0.5 \mathrm{~m}$ & $1.0 \mathrm{~m}$ & & \\
\hline 2 & 1.02 & 1.86 & 0.02 & $<0.001$ \\
\hline 3 & 0.76 & 1.30 & 0.04 & $<0.003$ \\
\hline 4 & 0.67 & 1.08 & 0.01 & $<0.001$ \\
\hline 5 & 0.56 & 0.92 & 0.01 & $<0.001$ \\
\hline 6 & 0.49 & 0.80 & 0.02 & $<0.002$ \\
\hline
\end{tabular}

${ }^{1}$ Distances were calculated from video recordings at 5 -min scan samples of 90-min postfeeding periods and were averaged for the 7 $\mathrm{d}$ per treatment for 4 groups of cows ( 6 cows per group) fed $2 \times \mathrm{d}$.

cally displaced another from the feed alley, was higher $(P<0.05)$ when animals had access to $0.5 \mathrm{~m}$ of feed alley space per cow $(1.55 \pm 0.17$; mean \pm LS SE) than with $1.0 \mathrm{~m}$ of feeding space $(0.66 \pm 0.17)$.

\section{Feeding Behavior}

Feeding activity was $14 \%$ higher, and total daily mealtime was $10 \%$ higher when cows were provided the $1.0 \mathrm{~m}$ treatment compared with the $0.5 \mathrm{~m}$ treatment (Table 2). These differences in feeding behavior between treatments were particularly pronounced at peak feeding times; feeding activity during the 90 -min PF period increased by $24 \%$ when cows were provided with more feeding space. This is further evidenced in Figure 1, where we see more animals at the feed alley with 1.0 $\mathrm{m}$ of feeding space during the time period immediately following the provision of fresh feed and return from milking.

Because there was a significant increase in PF feeding activity with more feeding space, we used linear regression to determine how the individual cows responded to the treatment (Figure 2). The coefficient of determination was statistically significant $(P<0.01)$.
The intercept $(158.90 \pm 29.76$; mean $\pm \mathrm{SE})$ was greater than zero $(P<0.001)$. Additionally, the cows with lower $\mathrm{PF}$ feeding activity when they had access to $0.5 \mathrm{~m}$ of feeding space showed greater increases with increased feeding space, as indicated by the slope $(0.48 \pm 0.13)$ for this linear relationship being significantly less than one $(P<0.001)$. Analysis of covariance demonstrated an interaction between response to treatment and index of success for PF feeding activity $(P<0.001)$. Those cows with a low index of success had greater increases in PF feeding activity when provided with more feeding space than those cows with a high index of success. Indeed, $31 \%$ of the variation in the individual change in PF feeding activity was explained by the individual's index of success $(P<0.001)$.

\section{DISCUSSION}

When provided with more space at the feeder, cows increased distances from their nearest neighbor, reduced their frequency of aggressive interactions, and increased feeding activity. There has been some previous research with other farm animals indicating that the distance between neighboring animals is dependent on the amount of space they are provided (Keeling and Duncan, 1989; Keeling, 1994; Sibbald et al., 2000). The one previous study of this type using dairy cattle also found that the distance to the nearest neighbor increased with increased floor space allowance (Kondo et al., 1989). In the current study, increased space at the feeder increased spacing between cows regardless of the number of cows present at the feed alley.

In this study, the range in inter-cow distances was greater when fewer animals were present at the feed alley, particularly with $1.0 \mathrm{~m}$ of feeding space. In a study with grazing sheep, Sibbald et al. (2000) found the highest range in nearest neighbor distances between grazing sheep was at the highest levels of space allowance. At the highest densities, the size of the animal

Table 2. Measures of feeding behavior ${ }^{1}$ with 0.5 and $1.0 \mathrm{~m}$ of allocated feed alley space per cow. The leastsquare SE and $P$ values for the test of treatment are provided.

\begin{tabular}{|c|c|c|c|c|}
\hline \multirow[b]{2}{*}{ Measures } & \multicolumn{2}{|c|}{ Feed alley space per cow } & \multirow[b]{2}{*}{$\mathrm{SE}$} & \multirow[b]{2}{*}{$P$} \\
\hline & $0.5 \mathrm{~m}$ & $1.0 \mathrm{~m}$ & & \\
\hline Daily feeding activity $^{2}$ & 1334.5 & 1520.9 & 24.51 & $<0.001$ \\
\hline Total daily mealtime ${ }^{3}$ & 279.0 & 307.6 & 4.26 & $<0.001$ \\
\hline Feeding intensity ${ }^{4}$ & 4.9 & 5.0 & 0.09 & 0.46 \\
\hline Post-feeding feeding activity ${ }^{5}$ & 210.2 & 260.7 & 11.18 & 0.004 \\
\hline
\end{tabular}




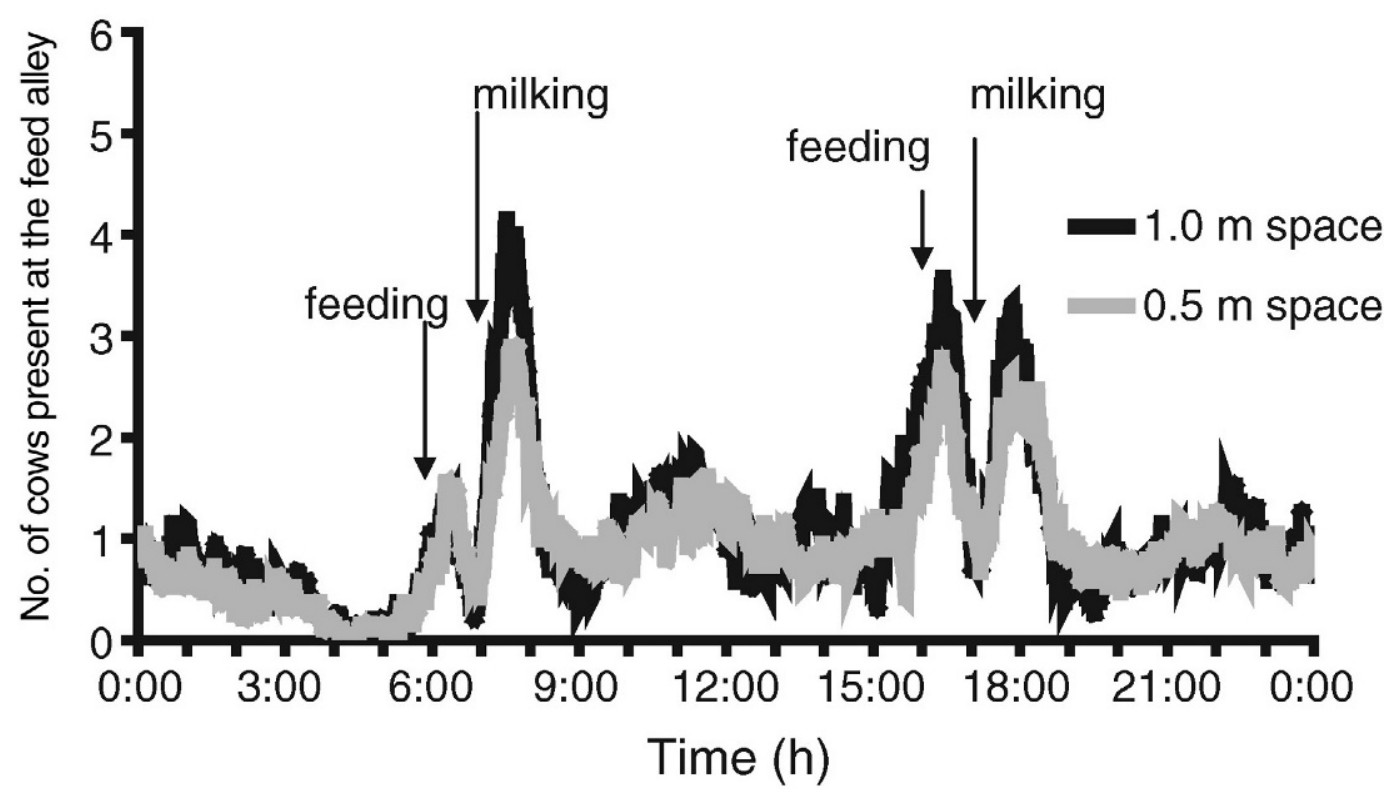

Figure 1. Number of cows per group present at the feed alley over a 24-h period (number for each 60 -s interval during the day) for both $0.5 \mathrm{~m}$ and $1.0 \mathrm{~m}$ feeding space per cow treatments. Data are averaged for $7 \mathrm{~d}$ per treatment for 4 groups, each containing 6 cows.

itself can create a lower limit to the space between 2 animals; as the amount of space provided at the feeder declines, nearest neighbor distances will tend to decline

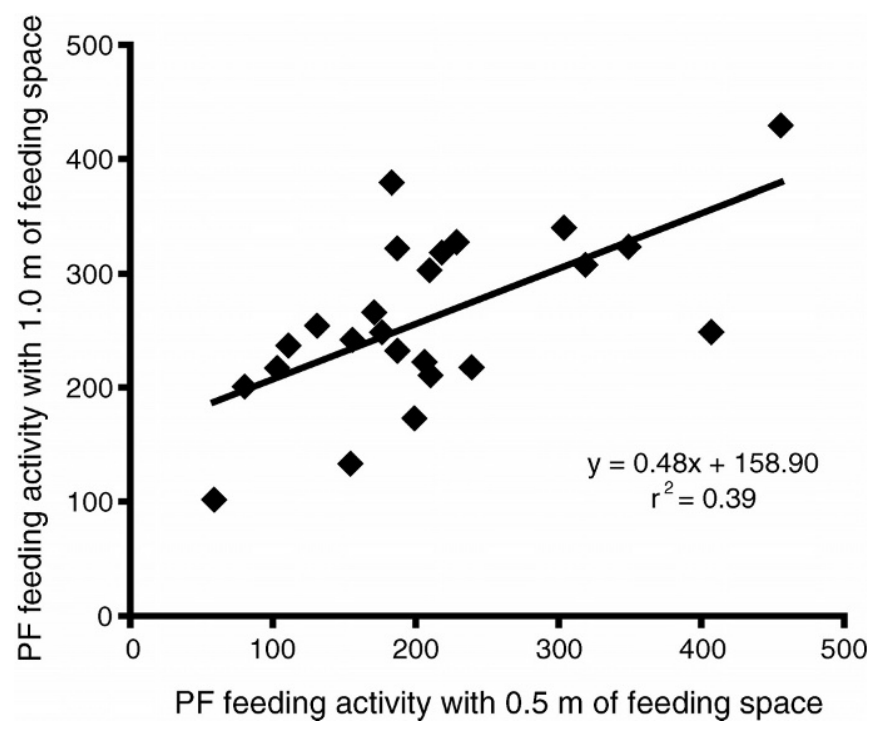

Figure 2. The relationship of postfeeding (PF) feeding activity (hits per 90-min PF period) measured on dairy cows with $0.5 \mathrm{~m}$ of feeding space per cow and with $1.0 \mathrm{~m}$ of feeding space per cow. The $\mathrm{PF}$ feeding activity was averaged for $7 \mathrm{~d}$ per treatment for 24 cows (4 groups of 6 ) fed $2 \times d$. to the limit of average body width. The hip width of Holstein dairy cows can exceed $0.5 \mathrm{~m}$ (Enevoldsen and Kristensen, 1997), and body width typically exceeds hip width. For this reason, the range in distance between cows when 6 cows were feeding with $0.5 \mathrm{~m}$ of feeding space feeding was very small.

Not surprisingly, given the larger distances between cows, there was also a change in the level of aggressive behavior with more feeding space. The average number of times a cow displaced another from the feed alley during the $90-\mathrm{min} \mathrm{PF}$ period when provided $1.0 \mathrm{~m}$ of feed alley space per cow was only $43 \%$ of the level seen during that same time period for the $0.5 \mathrm{~m}$ treatment. This finding contrasts with Collis et al. (1980), who reported no change in the amount of aggressive behavior when feeding space was reduced from 1.05 to 0.45 $\mathrm{m}$ of feeding space. Unfortunately, these authors had very few observations using only a single day of data for each treatment level; thus, making the reliability of their results difficult to assess. Typically, studies involving feeding space have looked at the effects of increased competition due to reduced feeding space. Olofsson (1999) found that the number of displacements within a group increased when cows went from having 1 to 4 cows per feeding station. However, the current study is the first to show that providing more feeding space than typically allocated can reduce aggression. 
In the current study, cows increased feeding activity but not feeding intensity when given $1.0 \mathrm{~m}$ of feed alley space compared with $0.5 \mathrm{~m}$. This effect was particularly evident during the $90-\mathrm{min} \mathrm{PF}$ period, with cows increasing feeding activity by $24 \%$ when given access to the higher amount of feeding space. This increase accounted for over $54 \%$ of the increase in daily feeding activity when provided access to the $1.0-\mathrm{m}$ treatment. These changes during the 90-min PF period were likely due to the increased spacing and decreased aggressive interactions; with more room to feed and less social hindrance at $1.0 \mathrm{~m}$ of feeding space, cows had more opportunity and time to consume their feed.

Despite the significant increase in PF feeding activity, there was substantial between-cow variation in this response. Cows that displayed the lowest PF feeding activity with $0.5 \mathrm{~m}$ of feeding space showed the greatest increase with $1.0 \mathrm{~m}$ of feeding space, and these cows also had the lowest index of success. Therefore, increasing feeding space to $1.0 \mathrm{~m}$ per cow allows subordinate cows to increase feeding activity at peak feeding times.

The current study is the first to demonstrate that feeding activity and total daily mealtime can be increased by providing more feeding space than typically used on dairy farms. Interestingly, previous studies (Friend et al., 1977; Collis et al., 1980) have indicated that feeding space can be reduced to as little as $0.2 \mathrm{~m}$ per cow without impairing DMI or total time spent eating. However, these earlier studies did not take into consideration the diurnal feeding pattern of cows and how feeding patterns change under situations of restricted feeding space. With $0.2 \mathrm{~m}$ of feeding space, many cows may not be able to gain access to the feed at peak feeding times, forcing them to shift their feeding times to other parts of the day, including late at night (Forbes, 1995). Georgsson and Svendsen (2002) reported that small pigs housed in groups with larger animals shifted their feeding behavior when only one feeder was present; namely, they consumed a larger proportion of their daily feed intake during the night time hours when compared with having access to 2 feeders. Such a shift in feeding time may be problematic for cows, because sorting of the TMR can reduce the quality of the feed for those who do not have access at the time fresh food is provided (Leonardi and Armentano, 2003). The results of the present study indicate that providing more feeding space improves access to fresh feed, particularly for the subordinate cows, which possibly reduces the variation in diet quality consumed by the cows. It has also been suggested that increased feed access and reduced competition may increase feed intake and decrease feeding rate, possibly reducing the risk for metabolic problems such as subacute ruminal acidosis and left displaced abomasums (Shaver, 1997; Shaver, 2002).

\section{CONCLUSIONS}

Increasing the feeding space from $0.5 \mathrm{~m}$ to $1.0 \mathrm{~m}$ per cow allowed animals to space themselves further apart while feeding and reduce their frequency of aggressive interactions. These changes in spacing and aggressive behavior in turn allowed cows to increase feeding activity in the time after the provision of fresh feed. This increase in feeding activity was particularly true for those subordinate cows that had limited PF feeding activity with $0.5 \mathrm{~m}$ of feeding space. We therefore recommend increased feeding space over the current industry standard to increase feeding activity and reduce aggressive interactions in lactating dairy cows.

\section{ACKNOWLEDGMENTS}

We thank the staff and students at The University of British Columbia's Dairy Education and Research Centre and the university's Animal Welfare Program. In particular, we thank Sara Piper for her help with the video analysis and Cassandra Tucker for her helpful comments concerning the manuscript. We also thank Agriculture and Agri-Food Canada's Lethbridge Research Centre for the use of their feeding behavior monitoring system. Trevor DeVries was supported by a Natural Sciences and Engineering Research Council of Canada Postgraduate Scholarship. The project was funded by the Natural Sciences and Engineering Research Council of Canada, through the Industrial Research Chair in Animal Welfare, and by contributions from the Dairy Farmers of Canada, the Beef Cattle Industry Development Fund, the BC Dairy Foundation, the BC SPCA, members of the BC Veterinary Medical Association, and many other donors listed on our Web site at http://www.agsci.ubc.ca/animalwelfare.

\section{REFERENCES}

Canadian Council on Animal Care. 1993. Guide to the Care and Use of Experimental Animals. Vol. 1. E. D. Olfert, B. M. Cross, and A. A. McWilliam, ed. CCAC, Ottawa, Canada.

Collis, K. A., M. J. Vagg, P. T. Gleed, C. M. Copp, and B. F. Sansom. 1980. The effects of reducing manger space on dairy cow behavior and production. Vet. Rec. 107:197-198.

DeVries, T. J., M. A. G. von Keyserlingk, and K. A. Beauchemin. 2003a. Diurnal feeding pattern of lactating dairy cows. J. Dairy Sci. 86:4079-4082.

DeVries, T. J., M. A. G. von Keyserlingk, D. M. Weary, and K. A. Beauchemin. 2003b. Measuring the feeding behavior of lactating dairy cows in early to peak lactation. J. Dairy Sci. 86:3354-3361.

DeVries, T. J., M. A. G. von Keyserlingk, D. M. Weary, and K. A. Beauchemin. 2003c. Validation of a system for monitoring feeding behavior of dairy cows. J. Dairy Sci. 86:3571-3574. 
Enevoldsen, C., and T. Kristensen. 1997. Estimation of body weight from body size measurements and body condition scores in dairy cows. J. Dairy Sci. 80:1988-1995.

Forbes, J. M. 1995. Voluntary Food Intake and Diet Selection in Farm Animals. CAB Int., Wallingford, UK.

Friend, T. H., and C. E. Polan. 1974. Social rank, feeding behavior, and free stall utilization by dairy cattle. J. Dairy Sci. 57:12141220.

Friend, T. H., C. E. Polan, and M. L. McGilliard. 1977. Free stall and feed bunk requirements relative to behavior, production and individual feed intake in dairy cows. J. Dairy Sci. 60:108-116.

Georgsson, L., and J. Svendsen. 2002. Degree of competition at feeding differentially affects behavior and performance of grouphoused, growing-finishing pigs of different relative weights. J. Anim. Sci. 80:376-383.

Grant, R. J., and J. L. Albright. 2001. Effect of animal grouping on feeding behavior and intake of dairy cattle. J. Dairy Sci. 84(E. Suppl.):E156-E163.

Keeling, L. J., and I. J. H. Duncan. 1989. Inter-individual distances and orientation in laying hens housed in groups of three in two different-sized enclosures. Appl. Anim. Behav. Sci. 24:325-342.

Keeling, L. J. 1994. Inter-bird distances and behavioural priorities in laying hens: The effect of spatial restriction. Appl. Anim. Behav. Sci. 39:131-140.

Kondo, S., J. Sekine, M. Okubo, and Y. Asahida. 1989. The effect of group size and space allowance on the agonistic spacing behaviour of cattle. Appl. Anim. Behav. Sci. 24:127-135.
Leonardi, C., and L. E. Armentano. 2003. Effect of quantity, quality, and length of alfalfa hay on selective consumption by dairy cows. J. Dairy Sci. 86:557-564.

Mendl, M., A. J. Zanella, and D. M. Broom. 1992. Physiological and reproductive correlates of behavioural strategies in female domestic pigs. Anim. Behav. 44:1107-1121.

Miller, K., and D. G. M. Wood-Gush. 1991. Some effects of housing on the social behaviour of dairy cows. Anim. Prod. 53:271-278.

National Research Council. 2001. Nutrient Requirements for Dairy Cattle. 7th rev. ed. Proc. Natl. Acad. Sci. USA, Washington, DC.

O'Connell, J., P. S. Giller, and W. Meaney. 1989. A comparison of dairy cattle behavioural patterns at pasture and during confinement. Ir. J. Agric. Res. 28:65-72.

Olofsson, J. 1999. Competition for total mixed diets fed for ad libitum intake using one or four cows per feeding station. J. Dairy Sci. 82:69-79.

Rook, A. J., and C. A. Huckle. 1995. Synchronization of ingestive behaviour by grazing dairy cows. Anim. Behav. 20:637-643.

SAS User's Guide: Statistics, Version 5 Edition. 1985. SAS Inst., Inc., Cary, NC.

Shaver, R. D. 1997. Nutritional risk factors in the etiology of left displaced abomasum in dairy cows: A review. J. Dairy Sci. 80:2449-2453.

Shaver, R. D. 2002. Rumen acidosis in dairy cattle: Bunk management considerations. Adv. Dairy Technol. 14:241-249. University of Alberta, Edmonton, Alberta, Canada.

Sibbald, A. M., L. J. F. Shellard, and T. S. Smart. 2000. Effects of space allowance on the grazing behaviour and spacing of sheep. Appl. Anim. Behav. Sci. 70:49-62. 